\title{
A Study of Applying Artifact-Metrics Technology and Baking Invisible Information onto Valuable Porcelain Products
}

\author{
Masaki Fujikawa and Shingo Fuchi
}

\begin{abstract}
In this paper, we propose a new method in order to verify the authenticity of porcelain product much easier by using artifact-metrics technology. In our method, counterfeiter cannot make copied product even if they could use same materials and tools which were used by the brand holder company or the ceramic artists. This method uses transparent glass phosphor powder to apply characteristic information on the surface of each product during glazing or/and painting on daily production, so that color tone created in the furnace is not affected. Our method requires no additional work for master artisan and no sophisticated skills for buyer. Besides, glass phosphor has no potential hazards to the human body and environment. In this paper, we indicate high feasibility of our method by showing results of some experiments. We also try to burn invisible information (QR code) onto the surface of each porcelain product.
\end{abstract}

Index Terms-Artifact-metrics, authenticity, glass phosphor, information hiding, near infrared rays, porcelain product, spectral imaging.

\section{INTRODUCTION}

Valuable porcelain products produced by brand holder company or prominent artist trade at high prices, and there are malicious persons trying to produce and sell counterfeit products [1]. These acts must not be ignored as in the case of counterfeit brand goods, such as bags and ornaments, and such acts not only violate the intellectual property rights of brand holders but violators gain an unfair amount of money by deceiving buyers.

As proof of authenticity of the products, brand holders paint their brand names or ID numbers on the shipped products. (For example, a porcelain producer engraves the brand name on the formed clay or hand paints ID numbers.) However, because counterfeit products that imitate such brand names and ID numbers are produced and sold [2], the above countermeasures are not decisive as proof of authenticity.

Generally, it is quite difficult to verify the authenticity of porcelain products in an expedient way, and it requires the experience, expertise, and skill of a person (i.e., connoisseur). Accordingly, there remains the risk of purchasing counterfeit products for resale purposes or selling counterfeit products as

Manuscript received April 7, 2015; revised July 13, 2015.

Masaki Fujikawa is with the ALSOK Security Science Institute, Ishijima, Tokyo 135-0014 Japan (e-mail: Fujikawa-masaki@alsok.co.jp).

Shingo Fuchi is with the Department of Electrical Engineering and Electronics, Aoyama Gakuin University, 5-10-1 Fuchinobe, Chuo-ku, Sagamihara-shi, Kanagawa 252-5258 Japan. authentic without knowing it if the verification skill is not adequate. (There was actually a case where a named department store sold leather goods to customers as authentic products that were actually counterfeit products because the buyer failed to identify the fraud [3]).

The authors believe that the technology should be established that makes fabrication of counterfeit porcelain products difficult and verification of authenticity easy even without sophisticated skills as is the case for value-bearing paper like bank notes. Because the design (shape, surface colors, etc.) is essential in these products, the technology must not impair the design of the product and must not require additional work by the master craftsman or artisan. The authors invented the new artifact-metrics that can be applied for individual porcelain products produced every day, which is introduced in this paper. In addition, we tried to burn invisible information ( $Q R$ code) onto the surface of each product.

\section{PREPARATIONS}

\section{A. What Artifact-Metrics Mean?}

Artifact-metrics is defined as "the technology used to authenticate the artifact making use of the peculiarities of such an artifact" [4]. While physical and/or behavioral peculiarities of a person are the criteria for authentication in biometrics, the characteristics (peculiarity information) that are incidentally created during production of the artifact are the criteria for the artifact. Authenticity of the artifact is determined by comparing the peculiarity information detected by the instrument with the peculiarity information registered beforehand, similar to biometrics. The system incorporating artifact-metrics is called the Artifact-metrics system (see Fig. 1).

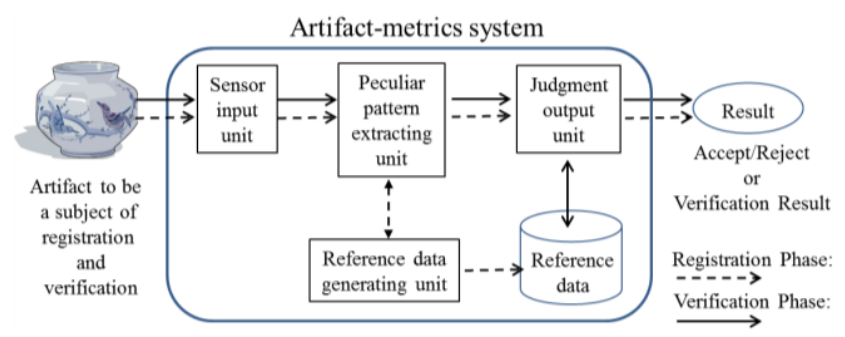

Fig. 1. Schematic diagram of the artifact-metric system.

Microscopically, peculiarity information differs for each individual artifact, but it is not easy to extract. In porcelain product, microscopic image of color tone, asperity, and tiny 
crack may be used, but it may take a donkey's years to be able to search the same imaging area due to microscope's narrow and limited observation range. Accordingly, in artifact-metrics technology, a certain material is added during production process to extract characteristic information easily For example in the case of reference [5], paper in which fine magnetic fibers (material) are woven is used for indenture documents (artifact), and the peculiarity information (magnetic signal) is extracted by scanning the document with a magnetic head.

In general, in artifact-metrics technology, magnetic, optical, electrical, or vibration characteristics which material has is used for extraction of characteristic information.

\section{B. Requirements of the Artifact-Metrics to Apply for Porcelain Products}

First, a material to be added to the artifact (porcelain product) to make extraction of the peculiarity information easier should not affect the color generated during firing by clay, glass, glaze, and paint and should not be harmful to human body and the environment. Next, the addition of such material to the artifact should not require additional work for the craftsman to keep productivity. Furthermore, the method used to extract peculiarity information should not adversely affect the artifact. Based on the above considerations, the following requirements are established for artifact-metrics.

1) The risk of affecting the colors generated by the clay, glass, glaze, and paint of a material added to the artifact must be low: Colors are not be affected by material.

2) The risk of affecting human body and the environment by the material must be low: Using of harmful material is prohibited.

3) The addition of the material to the artifact must not require additional work by the craftsman: We cannot force them to require such work.

4) The peculiarity information can be extracted contactless and in a short time: We should avoid damaging porcelain product during extraction.

\section{Prerequisites}

To define the scope of the discussion, the following prerequisites are established.

Condition 1: In this paper, goods produced by the manufacturer every day are discussed. This means that goods already traded in the market or held by collectors (antiques etc.) are not included.

Condition 2: In this paper, the potential capability of the artifact-metrics proposed by the authors (capability to verify authenticity of the porcelain products) is discussed. Because the authors have not implemented the proposed method, detailed discussions of artifact-metrics (e.g., evaluation of capability of pattern matching devices or evaluation of clone resistance) are not provided.

Condition 3: Counterfeit products mean products that are produced not using the manufacturer's genuine production process and bear false claims that they are made by such manufacturer (mimicking the design or engraving, etc.).

Condition 4: Although the authors had not implemented the proposed artifact-metric system, discussions are based on the presumption that a reliable artifact-metrics system and trustworthy players (manufacturer, buyer, and retailer) are available.

Condition 5: Pottery and affordable electric furnace are used for confirmation of our method's effectiveness because strict temperature management during firing is not needed compared with porcelain.

\section{OUR ARTIFACT-Metrics TECHNOLOGY}

\section{A. Material to be Added in the Porcelain Products}

Glass phosphor [6] that is highly transparent and emits near infrared rays (peak wavelength of 1,000 nm) when irradiated by laser beam (optical excitation) drew the attention of the authors as the candidate material satisfying Requirements 1 and 2 above. Glass phosphor is produced by melting a mixture of powders consisting of small amounts of rare earth oxides and the supporting glass, which has the following characteristics.

- As rare earth oxides that are relatively easily available are used and the weight ratio to the supporting glass is just a few percent, the production cost is low.

- Because the main component is glass, the material is compatible with the glaze and paint as vitreous materials. It can be welded and united with the glaze and paint during firing process.

- The risk of doing harm to human body (skin etc.) and the environment is low.

Color, transparency, and conversion efficiency from laser light to infrared rays of the glass phosphor are determined by the type and ratio of the rare earth oxides and the composition of the supporting glass. After examining the composition, we produced glass phosphor in which the color was reduced and transparency was improved (see Fig. 2 and Fig. 3).

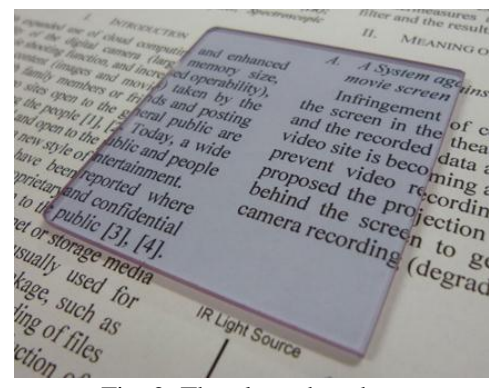

Fig. 2. The glass phosphor.
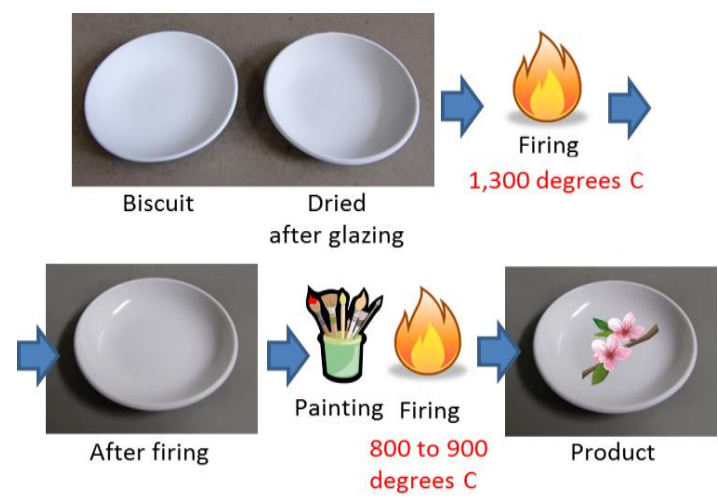

Fig. 3. Production process of porcelain. In our method, glass phosphor powder is added on the surface of product during glazing and/or painting process. 
In Section IV, we use this one for experiments as material. While the glass phosphor we are seeking is completely colorless and transparent, the material has pale blue tint at present. While the authors continue to eliminate coloring because it is intended only to explain the concept and effectiveness of glass phosphor in this paper, verification of the following points was aimed in the experiment.

- Difficulty in visual identification: Only a small quantity of the glass phosphor will be added in the artifact considering the color of the glass phosphor, and it should be confirmed that a pale blue color is not easy to identify (i.e., addition of the glass phosphor cannot be known visually).

- Irradiation of infrared rays: It should be confirmed that the glass phosphor added in the artifact must irradiate low intensity infrared rays caused by optical excitation.

\section{B. Addition of Material and Extraction of Peculiarity Information}

We propose a method to add glass phosphor in the application of the glaze or paint in order to satisfy requirement 3 . In this method, a security company produces and supplies glaze or paint that contains fine glass phosphor powder to the workshop. As no additional work is required, the glass phosphor can be added to the artifact during the usual work by the craftsman (i.e., application of glaze or paint). Particles of the glass phosphor in the glaze or paint are deposited on the surface of the artifact with the components of the glaze or paint during the firing process, which comes after dipping and painting. During these processes, the position of the particles and the degree of bonding of the particles are incidentally and randomly determined and are different between individual products. Such information is used as the peculiarity information.

We propose a method to photo-shoot the surface of the artifact illuminated by laser light to extract the peculiarity information that satisfies requirement 4 . This is because the positions of the particles and the degree of bonding between particles correspond to the irradiating positions and the intensity of infrared rays due to the irradiation of laser light. When the information extracted as above is recorded in the reference data shown in Fig. 1, the judgment of authenticity of the products becomes possible. Our method makes non-contacting and quick extraction of the peculiarity information possible, and the risk of adversely affecting the product is small because no ultraviolet rays, electromagnetic waves, or radioactive rays are used for extraction. The originality of our method is to observe illuminating pattern of material by optical excitation. (Previous works irradiate artifact with light and observe reflected or transmitted light component [7]-[16].)

\section{Difficulty of Creating Same Peculiarity Information}

Counterfeiter may think that the amount of infrared rays can be adjusted by selecting and accumulating particles properly. We therefore explain the difficulty of creating same characteristic information by such way. In a simple way, we can assume three types of particles and its infrared light pass (see Fig. 4), and counterfeiter intend to emit IR light to only Z axis (see Fig. 5).
However, in reality, emitted IR ray from particle (1) may have another three passes and could be observed on another space (XY, YZ, or ZX space) due to neighboring particle's boundary (see Fig. 6). Besides, particle's shape is not spherical (it has random asperity), so that's why it is quite difficult to adjust the number of IR rays by selecting and accumulating particles while referring IR spectral image of genuine product.

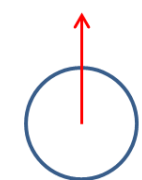

(1)

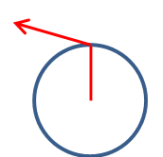

(2)

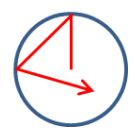

(3)
Fig. 4. Infrared light pass.

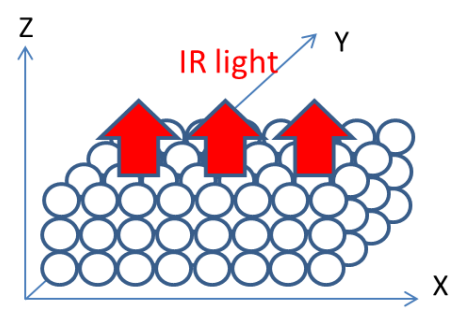

Fig. 5. Approach of IR emission to $Z$ axis

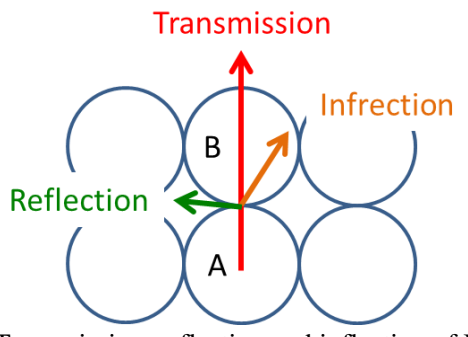

Fig. 6. Transmission, reflection and inflection of IR rays.

\section{EXPERIMENTS}

\section{A. Experiment 1 (Difficulty in Visual Identification)}

White unglazed plates were used so that the blue color could be easily identified, and 5 plates with glass phosphor deposition and 5 plates without deposition for a total of 10 plates were produced. Although we proposed the addition of the glass phosphor by dipping or painting, the following procedures (1) and (2) were used for convenience in order to investigate the appropriate proportion of the glass phosphor in the glaze and paint and to verify that very small amounts of the glass phosphor have the same effect.

1) Unglazed plates were dipped in the glaze that becomes clear after firing, taken out, and dried.

2) Five plates were randomly selected from the 10 dried plates on which the surface mixture of the glass phosphor powder and ethanol was applied and dried. Portions where glass phosphor was applied were smoothed with a fingertip to spread out the glass phosphor particles to reduce the thickness of the glass phosphor layer.

3) Plates were placed in the furnace. After the temperature was increased to 1,230 degrees $\mathrm{C}$ for 8 hours, the furnace was left to cool naturally to room temperature. Then, the plates were taken out of the furnace and an identification mark was applied to the back of five plates to indicate the 
application of the glass phosphor.

Two types of plate created in above process are shown in Fig. 7. Next, the following tests were conducted for 60 subjects after explaining the purpose of the experiment and the characteristics of the glass phosphor and the transparent glaze.

1) The experimenter selected 5 plates randomly from 10 plates outside the vision of the subjects.

2) After the subjects looked at the selected plates for 15 seconds, the subject was asked to answer whether each plate was deposited with the glass phosphor or not to the experimenter. The subjects were not allowed to examine the plates by hand.

3) After the subject answered the question, the experimenter looked at the back of the plate to see whether the glass phosphor was deposited, and 10 points were awarded for each correct answer. The subjects were not notified whether their answers were correct.

4) The experimenter repeated steps (1) and (3) 10 times to calculate the ratio of correct answers for the respective subjects.

Tables I and II shows the test results. No subjects attained a correct answer rate exceeding 50\%. This indicates that the glass phosphor is potentially effective and the identification of the color pale blue is difficult provided that it is deposited in small quantities (identification of the addition of the glass phosphor is visually difficult).

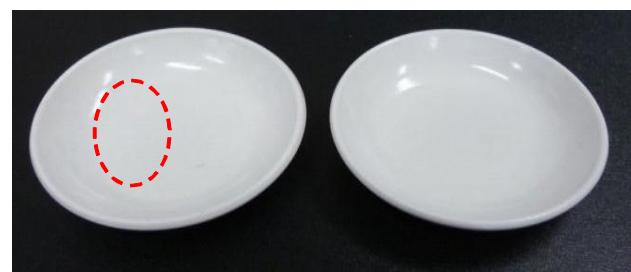

Fig. 7. Light: With glass phosphor. The material is added in the area of dashed line. Right: without glass phosphor.

TABLE I: LEFT: CORRECT ANSWER RATE OF EACH SUBJECT (SCATTER CHART). THE Average Was 0.458

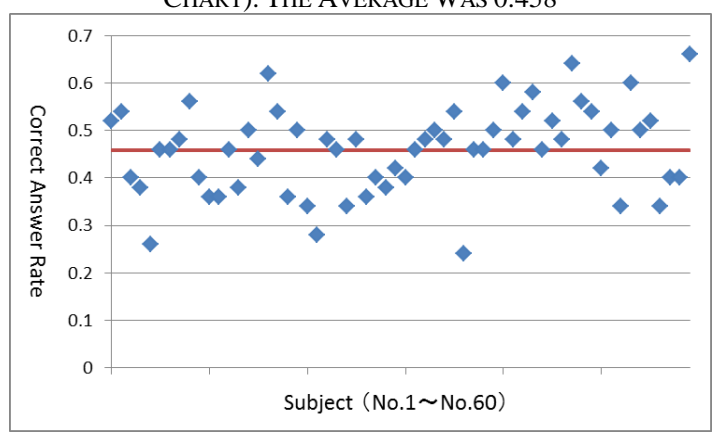

TABLE II: GRAPH OF FREQUENCY DiSTRIBUTION. PEAK OF ANSWER RATE WAS ABOVE 0.4 TO BELOW 0.5

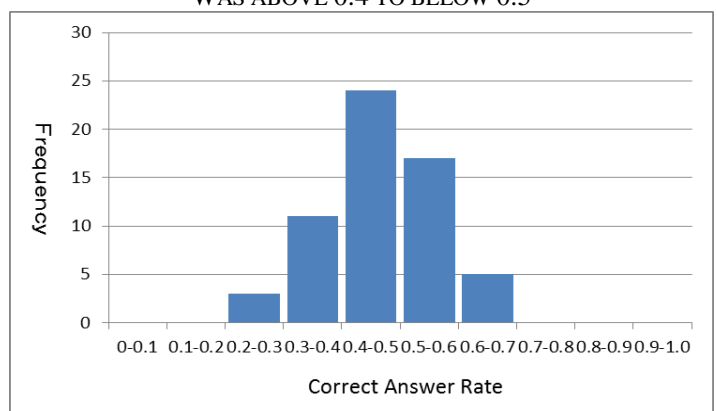

\section{B. Experiment 2 (Irradiation of Infrared Rays)}

Infrared spectral images were taken with a camera by irradiating $808 \mathrm{~nm}$ laser beam on two types of the plates prepare in experiment 1 . The camera with an InGaAs image sensor sensitive to near infrared rays was used, and the optical filter that selectively passes infrared rays (IR85, RG830) was attached in front of the camera lens (see Fig. 8).

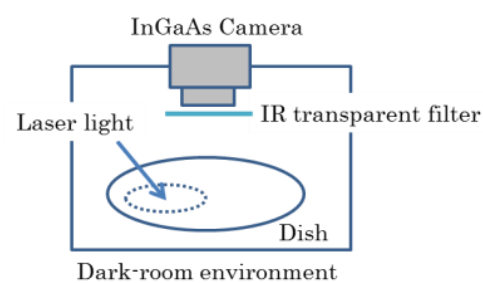

Fig. 8. Experiment environment. Infrared spectral images were taken by InGaAs camera with IR filter.

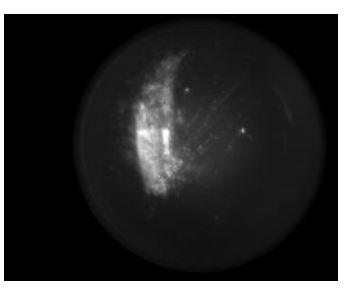

No.1

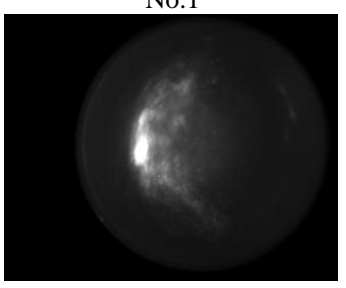

No. 3

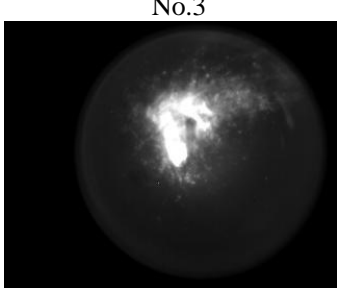

No.5

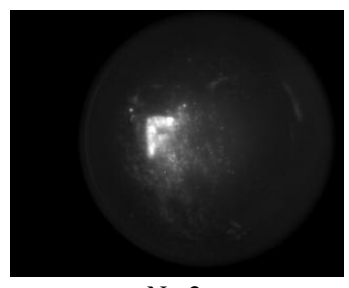

No.2

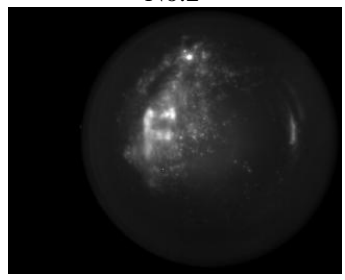

No.4

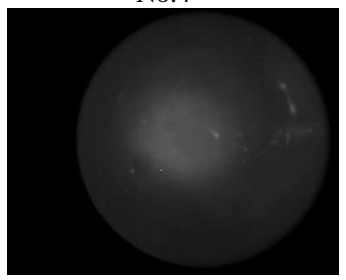

No. 6

Fig. 9. Infrared spectral image of each plate.
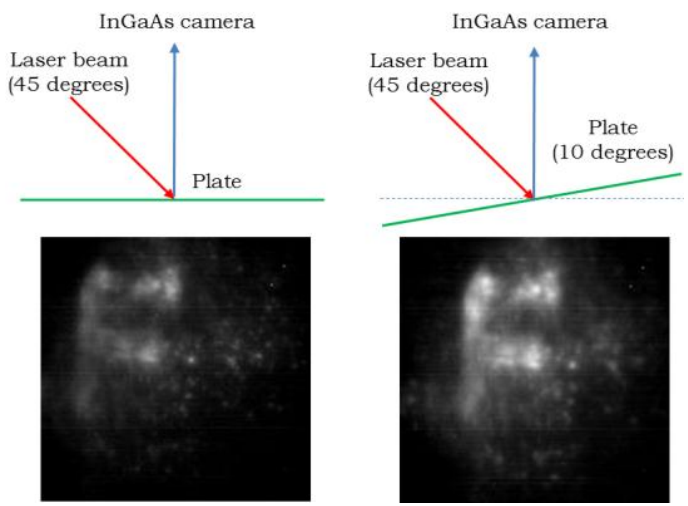

Fig. 10. Magnified infrared spectral images of plate No. 4

The intensity of infrared rays is recorded as the intensity of brightness in the spectral image. Fig. 9 shows the infrared spectral image. Irradiation of infrared rays was visible from the plate on which the glass phosphor was deposited (see from No. 1 to No. 5) but none from the plate without deposited glass phosphor (see No. 6). Spectral images of the plates with 
deposited glass phosphor are different, respectively. Fig. 10 shows the magnified infrared spectral image regarding plate No. 4. Different spectral images are observed when we made an angle of 10 degrees to InGaAs camera. This result proves our consideration (Difficulty of creating same characteristic information) described in Section III.C. From the above, it was confirmed that the glass phosphor continues to irradiate infrared rays due to optical excitation after firing, even in small quantities, and the infrared spectral image can be used as the peculiarity information.

\section{DISCUSSION}

In this section, the discussion is to what extent the requirements are satisfied under the proposed method, and the counterfeiting prevention technology is evaluated. In Section V.C, we also describe the feasibility of burning the invisible information (QR code) on the surface of porcelain product based on the elementary test.

\section{A. Satisfaction of the Requirements}

Requirement 1: As shown in Fig. 2, the glass phosphor has a pale blue tint at present. So when the glass phosphor is applied as a thick layer on the artifact, it is considered that the risk of affecting the colors generated by clay, glass, glaze, or paint is high. On the other hand, when a very small amount of glass phosphor is applied to the artifact, the presence of the glass phosphor is visually difficult to identify as the results of experiment 1 indicate, and it may be considered that the risk of affecting the colors generated by clay, glass, glaze, or paint is small. Considering the above, the proposed method at this stage satisfies the requirement, although certain conditions apply (reduction of amount of glass phosphor attached on the artifact).

Although some transparent materials exist, each candidate has problem to apply for the porcelain products (see Table III) This shows the advantage of glass phosphor for practical use.

TABLE III: COMPARISON BETWEEN GLASS PHOSPHOR AND OTHER MATERIAL

\begin{tabular}{|c|c|}
\hline Material & Consideration \\
\hline $\begin{array}{l}\text { Transparent } \\
\text { magnetic } \\
\text { substance }\end{array}$ & $\begin{array}{l}\text { The magnetizing process is required after firing } \\
\text { because the magnetic force wanes at high heat during } \\
\text { firing. }\end{array}$ \\
\hline $\begin{array}{l}\text { Transparent } \\
\text { conductive } \\
\text { material }\end{array}$ & $\begin{array}{l}\text { It loses transparency above } 600 \text { degrees } \mathrm{C} \text { during } \\
\text { firing. }\end{array}$ \\
\hline $\begin{array}{l}\text { Quartz with rare } \\
\text { earth } \\
\text { oxide }\end{array}$ & $\begin{array}{l}\text { It cannot melt } 1200 \text { to } 1300 \text { degrees } C \text { during firing. It } \\
\text { melts above } 1550 \text { degrees } C \text {. }\end{array}$ \\
\hline Glass phosphor & $\begin{array}{l}\text { It melts } 1200 \text { to } 1300 \text { degrees } \mathrm{C} \text { and doesn't lose its } \\
\text { function (transparency and IR emission) after firing. }\end{array}$ \\
\hline
\end{tabular}

Requirement 2: While small amounts of rare earth elements (neodymium, ytterbium, samarium, praseodymium, etc.) are used to produce the glass phosphor, the expert opinion is that no apparent toxicity can be observed from the rare earth elements. Materials of the supporting glass (oxide glasses of boron oxide system, phosphoric acid system, and boron anhydrate system) are stable oxides that are incombustible and insoluble, and it is said toxicity is very low. For example, lead oxide is contained in high quality transparent glass called crystal glass, and such glass is used as tableware, which indicates that the safety of such glass is high. Furthermore, glass phosphor, which is the compound between rare earth elements and the supporting glass, is a stable oxide glass that is incombustible and insoluble. As explained above, glass phosphor added to the artifact is less risky in affecting human health and the environment and satisfies the requirement. However, in handling glass phosphor powder, care should be taken to prevent inhalation and adhesion of the particles to the eye.

Requirement 3: The authors propose that a security company produces the glaze and paint containing fine glass phosphor powder and supplies them to the workshop of the artifacts. The production process will not be required to change because the glass phosphor can be applied to the artifacts via the ordinary work of the craftsman (application of the glaze or painting). This means that the proposed method will satisfy the requirement. In certain workshops, preparation of the glaze and paint is made by the craftsman. In such a case, a new work step to add the proper amount of glass phosphor has to be included in the production process.

Requirement 4: As explained in Section IV, the infrared spectral image representing peculiarity information of the product can be obtained without contact with the product in a short exposure time (fast shutter speed). This means the proposed method satisfies the requirement. In order to obtain the peculiarity information of the products quickly and effectively, it is necessary to know where the glass phosphor is deposited on the product.

\section{B. Evaluation}

For the evaluation of the counterfeiting prevention technology, it is at least necessary to consider security, convenience, cost, and social acceptance [17]. While the authors determined the potential effectiveness of the proposed method in Section IV, the system is not implemented yet. Accordingly, the authors evaluated each element based on the results of experiments and carried out a study towards system implementation.

\section{1) Security}

Evaluation of our method: As it is considered almost impossible to manipulate positions and the bonding of glass phosphor particles deposited on the artifact in the furnace, it is difficult to produce counterfeit products even if a malicious person were to obtain the genuine product to copy it.

Study towards system implementation: As far as the security of the artifact-metrics system shown in Fig. 1 is ensured, a malicious person cannot register the data for counterfeit products in the reference data, and thus distribution of the counterfeit product as a genuine product becomes impossible. In this artifact-metrics system, certain variations exist between the respective optical systems to obtain peculiarity information (infrared spectral images), and because environmental conditions (e.g., positions where the product and the camera are placed, lighting condition, etc.) vary between the systems, the peculiarity information registered in the reference data and the peculiarity information obtained for verification of the product will not completely match. In the system to be implemented, certain thresholds must be incorporated to allow such variations, but 
this may also determine a counterfeit product as the genuine product subjected to a brute force attack [17], wolf attack [17], and hard copy attack [17]. So, the system is required to establish the thresholds considering such possible attacks.

\section{2) Convenience}

In this section, the ease of adding a material to the artifact and the ease of detecting peculiarity information are discussed.

Evaluation of our method: With respect to the ease of adding a material, because no additional work process is required as explained in Section V.A, we can say material addition is easy. With respect to detection of peculiarity information, it can be obtained simply and easily by photo shooting the products with an exciter light as explained in Section V.A, and we can say detection of the peculiarity information is easy.

Study towards system implementation: With respect to the ease of adding the material, smoothness must be increased by making the glass phosphor into a fine powder so that a craftsman will not feel differently when applying glaze or paint. With respect to the ease of detecting peculiarity information, information on the position where material is deposited must be easily available to the verifier as explained in Section V.A. For example, an instruction manual indicating such position should be attached to the products and posted on the manufacturer's website.

\section{3) Production cost of glass phosphor}

The cost of the glass phosphor per one piece of the product is discussed here.

Evaluation of our method: While a thin layer of glass phosphor was created by smoothing out the material with a fingertip, the thickness of the layer is not measured. Accordingly, it is assumed that the glass phosphor is spread over an area $20 \mathrm{~mm}$ square and the thickness of the layer is about the diameter of hair $(0.08 \mathrm{~mm})$. As the mass of the glass phosphor shown in Fig. 2 (50 mm square and thickness of 3 $\mathrm{mm}$ ) is $22 \mathrm{~g}$, the mass of the glass phosphor layer $(20 \mathrm{~mm}$ square and thickness of $0.08 \mathrm{~mm}$ ) becomes $0.094 \mathrm{~g}$ (using this number, appropriate mixture of glass phosphor in the glaze or paint can be obtained). The glass phosphor block in Fig. 2 was cut from $1 \mathrm{~kg}$ of glass phosphor. To make $1 \mathrm{~kg}$ of glass phosphor 3,344.95 USD was required, which means that $0.094 \mathrm{~g}$ of glass phosphor costs 0.31 USD. This value is less than the average price of an RFID tag of the same size (0.8-1.20 USD). Affixing the RFID tag may impair the design of the product, but deposition of the glass phosphor will not, because identification of the glass phosphor is difficult. As discussed above, we can say the glass phosphor is a cost effective security material.

Study towards system implementation: The above values are the charge when $1 \mathrm{~kg}$ of the glass phosphor is produced on a trial basis. The points are that easily available rare earth oxides are used to produce the glass phosphor and they occupy only a few weight percent of the supporting glass (a few grams per $100 \mathrm{~g}$ of the supporting glass). In practical application, a large amount of glass phosphor will be produced, and it will be possible to obtain glass phosphor for less than the value explained above.

\section{4) Social acceptance}

The safety of the glass phosphor and the feasibility of expanded use of the proposed method (acceptability of the method) are discussed here. Safety was already discussed in Section V.A and therefore the discussion is not repeated.

Evaluation of our method: While experience and special expertise and skills are required for verification of the authenticity of valuable porcelain products, the proposed method, when used, may allow a person without such expertise and skills to determine the authenticity of such products. Because of the above, the proposed method is likely to be employed in the business of valuable porcelain products not only by parties upstream of the business (authorized distributor, trading firm, etc.) but also by parties downstream (second-hand goods traders, consumers, etc.), and we can say that the proposed method is easily accepted by society.

Study towards system implementation: So that the proposed method is widely accepted by society, the authors consider that development of an inexpensive and accurate artifact-metrics system and the development of inexpensive tools that can easily determine authenticity are required, like in the case of the verification method for bank notes or securities. At this moment, construction of the artifact-metrics system requires a large investment, and no method that can be easily used for verification of authenticity is available, and the authors consider measures and methods that solve such issues are required for implementation of the system.

\section{Information Hiding: Burning the Invisible QR Code}

In this section, we consider the feasibility of burning the invisible information (QR code) onto the surface of porcelain product. The purpose of this is to record the related data (e.g., brand holder's name, production date, title, serial number, etc.) as a reference of authenticity because ordinary visible QR code affects porcelain's design, patterns, and colors. Although the current glass phosphor has pale blue, we assume that the colorless glass phosphor may be produced by future research progress. Therefore, we confirm that the less-visible QR code can be burned onto the surface of porcelain product by using current glass phosphor. We also discuss the proper method which can extract the information contained in the above code.

Generally, porcelain manufacturer uses the decal printing sheet to print patterns on the surface of porcelain product. Unlike with hand painting, this sheet is suitable for mass production. In this method, first of all, patterns are printed on the surface of printing sheet by using screen printing ink. After the detachment of the transparent thin layer with ink from decal printing sheet by water immersion, manufacturer applies this layer on the surface of porcelain with glaze (i.e., the product after the first firing) and dries. After that, patterns are burned by second firing process.

In our idea, invisible QR code could be formed by preforming $\mathrm{QR}$ code on the decal printing sheet by making proper screen printing ink. This ink can be made from glass phosphor powder and vehicle which contains resin and solvent, so that's why we can conduct the experiment to confirm the visibility evaluation of burned QR code by adjusting the proportion of glass phosphor powder to vehicle.

We prepared four types of printing inks (ink_1 to 4: See 
Table IV) by adjusting the amount of vehicle and glass phosphor powder, and made four types of decal printing sheets (sheet_1 to 4 ) with $4 \mathrm{~cm}$ square QR code printed by each ink. Next, we prepared white plates (plate_1 to 4) and applied each transparent thin layer on the surface of each plate respectively. After that, we burned those 800 degrees $\mathrm{C}$ for 10 minutes.

We confirmed that the QR code with different consistency could be formed on the surface of porcelain respectively and it was hardly visible when the consistency of glass phosphor was $5 \%$. However, the information contained in $5 \%$ QR code couldn't be seen to be extracted by using image processing because optical excitation was not enough due to the wide laser irradiation area (over $4 \mathrm{~cm}$ square). To solve this, spot laser source and two-dimensionally liner scanning IR spectral imaging system should be needed to obtain sharply-defined IR spectral image from 5\% QR code (see Fig. 11).

TABLE IV: SPECIFICATION OF EACH INK

\begin{tabular}{lcc}
\hline \hline No. & Consistency & Specifications (glass phosphor : vehicle) \\
\hline ink_1 & $5 \%$ & $5: 95$ \\
ink_2 & $10 \%$ & $10: 90$ \\
ink_3 & $30 \%$ & $30: 70$ \\
ink_4 & $50 \%$ & $50: 50$ \\
\hline \hline
\end{tabular}
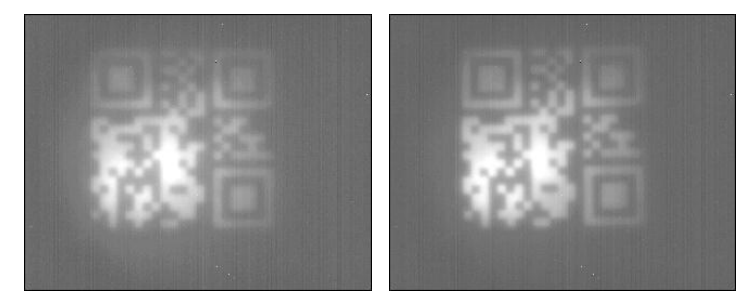

Fig. 11. Infrared spectral images (Left: 30\%, Right: 50\%) information contained in both QR code could be seen to be extracted by image processing.

\section{CONCLUSION}

The authors proposed artifact-metrics that make verification of authenticity of valuable porcelain products possible and make production of counterfeit products difficult The method satisfies the four requirements defined beforehand. The concept of the authors and the effectiveness of the glass phosphor at this stage were confirmed by basic experiments.

The glass phosphor aimed by the authors should be completely transparent and colorless, but it is pale blue tinted at this stage. The authors intend to examine the composition of the glass phosphor to eliminate any color tint to obtain a completely transparent and colorless material.

Pottery products were used in the experiment because temperature control in firing is easy, and the intention is to conduct similar experiments for porcelain products to verify the effectiveness of the concept and the glass phosphor. The authors intend to promote and expand the use of the proposed method while investigating the need for the method through interviews with manufacturers and potters and to resolve the issues discussed towards implementation.

\section{REFERENCES}

[1] MeissenPorcelain.com. (July 2013). Meissen porcelain reproductions $\begin{array}{lll}\text { and fakes. } & \text { [Online]. Available: }\end{array}$ $\mathrm{http} / / /$ meissenporcelain.com/meissen-porcelain-reproductions/
[2] L. Marion. (July 2013). Fake porcelain marks: Recognizing forged or imitation marks on ceramics. [Online]. Available: http://www.worthpoint.com/blog-entry/fake-porcelain-marks-recogni zing-forgedor-imitation-marks-ceramics/

[3] JNEWS.com. (July 2013). [Online]. Available: http://www.jnews.com/business/digest/2007/012.html/

[4] M. Yamakoshi et al., "An artifact-metrics which utilizes laser speckle patterns for plastic ID card surface," in Proc. SPIE, 2010.

[5] H. Matsumoto et al., "An artifact-metric system which utilizes inherent texture," IPSJ Journal, vol. 42, no. 8, pp. 139-152.

[6] S. Fuchi et al., "Wideband infrared emission from $\mathrm{Yb}_{3}{ }^{+}-$and $\mathrm{Nd}_{3}{ }^{+}$-doped $\mathrm{Bi}_{2} \mathrm{O}_{3}-\mathrm{B}_{2} \mathrm{O}_{3}$ glass phosphor for an optical coherence tomography light source," Japanese J. of Applied Physics, pp. 7932-7935.

[7] S. Ravikanth, "Physical one-way functions," Ph.D. thesis, Massachusetts Institute of Technology, 2001.

[8] L. D. Poli, Security Seal Handbook, Sandia Report, Sandia National Laboratory, 1978, pp. 1-44.

[9] Š. Boris et al., "Experimental hardware for coating PUFs and optical PUFs," Security with Noisy Data, Springer, 2007, pp. 255-268.

[10] P. Tuyls, Š. Boris, S. Sjoerd, M. H. A. Akkermans, and W. Ophey, "Information-theoretic security analysis of physical uncloneable functions," Financial Cryptography, 2005, pp. 141-155.

[11] National Research Council of the National Academies, "Counterfeit Deterrent Features for the naaext-generation currency design," National Academy Press, pp. 74-75, 1993.

[12] R. N. Goldman, “Non-counterfeitable System,” U.S. Patent 4786 290, 1988.

[13] V. Renesse and R. Leopold, "3DAS: A 3 dimensional-structure authentication system," European Convention on Security and Detection, pp. 54-59, 1995.

[14] D. Brzakovic and N. Vujovic, "Authentication of random pattern by finding a match in an image database," Image and Vision Computing, vol. 14, pp. 485-499, 1996.

[15] R. D. J. Buchanan et al., "Forgery: 'Fingerprinting' documents and packaging," Nature, vol. 436, p. 475, 2005

[16] M. Yamakoshi, T. Junichi, M. Furuie, M. Hirabayashi, and T. Matsumoto, "Individuality evaluation for paper based artifact-metrics using transmitted light image," in Proc. SPIE, 2008, vol. 6819, pp. $68190 \mathrm{H}-1-68190 \mathrm{H}-10$

[17] M. Une, U. Tamura, and T. Matsumoto, "Gi Zou boushi gijyutsu no nakano jinkoubutsu metrics (security kenkyu kaihatsu no doukou to kadai)," Bank of Japan, Research Paper (Japanese text), p. 147.

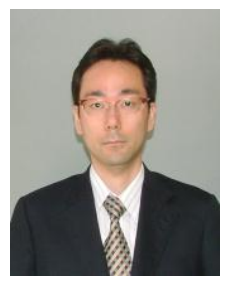

Masaki Fujikawa was born on February 6, 1974 in Tokushima, Japan. He received his master's degree in information engineering in 1998 from Tokushima University, Tokushima Prefecture, Japan. In 2004, he received his $\mathrm{Ph} . \mathrm{D}$. degree in information engineering from Chuo University, Tokyo, Japan.

He joined security service company ALSOK, in Tokyo Japan in 1998. From October 2002 to March 2011, he doubled as a guest researcher of the Research and Development Initiative, Chuo University. From November 2010 to Mach 2012, he was the director of an information security R\&D project of METI (Ministry of Economy, Trade and Industry, Japan). Now, he is one of the chief researchers of his company, and researching on different security and safety systems in order to build a safer society.

Dr. Fujikawa is a member of IEEE, IPSJ and the steering committee of the IPSJ Computer Security Group. Dr. Fujikawa received best paper and specially selected paper awards from IPSJ and best demonstration award from the 4th IFIP WG 11.11 International Conference on Trust Management 2010 .

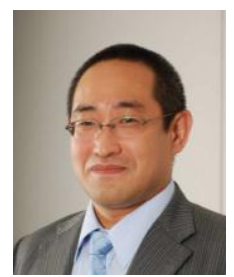

Shingo Fuchi was born in Hyogo, Japan, in 1975. He received his master's and Ph.D. degrees in materials science and engineering from Nagoya University in 1999 and 2002, respectively.

$\mathrm{He}$ is an associate professor in the Department of Electrical Engineering and Electronics at Aoyama Gakuin University, Sagamihara, Japan. Before coming to Aoyama Gakuin University, he was a patent examiner at Japan Patent Office, and an assistant professor in the Department of Crystalline Materials Science at Nagoya University. His research interests are semiconductor crystal growth, rare-earth doped glasses, and optical device application. He has published over 40 reviewed papers. Dr. Fuchi is a member of JSAP. 